\title{
APRESENTAÇÁO
}

\section{RETORNO A ÉMILE BENVENISTE: RETROSPECTIVAS E PERSPECTIVAS DE UMA TEORIA DA LINGUAGEM}

\author{
Irène Fenoglio (ITEM- CNRS/ENS) \\ Valdir do Nascimento Flores (UFRGS/CNPq)
}

O grande psicanalista Jacques Lacan, em um importante texto publicado em $1956^{1}$ e republicado em 1966, declara a propósito da urgência de a psicanálise retornar a Freud: "o sentido de um retorno a Freud é um retorno ao sentido de Freud” (LACAN, 1998 [1966], p. 406). Com isso, Lacan lembrava a necessidade de rever noções, textos e conceitos enfraquecidos pelo uso rotineiro para que se voltasse a ver neles a reflexão sobre os fundamentos da psicanálise. Anos mais tarde, o linguista JeanClaude Milner faz uso da mesma ideia de retorno, desta vez em relação a Saussure. Em um texto intitulado "Retour à Saussure" [Retorno a Saussure]2, Milner argumenta que a linguística de Saussure "obriga os linguistas a não tomar nada como evidente; mesmo aqueles que se afastaram dela deveriam retomar, etapa a etapa, o itinerário teórico do Curso e enfrentar as objeçôes, explícitas ou implícitas, que dele decorrem" (MILNER, 2008 [2002], p. 48, grifo do autor, tradução minha).

O que o gesto do psicanalista e o do linguista - cada um a seu modo - nos ensinam? Que um retorno nunca é apenas a reiteração do mesmo; ele sempre se faz acompanhar da instauração do novo. Quer dizer, na verdade, não há um ponto de vista "neutro" a partir do qual possamos simplesmente retornar a algo; isso sempre é feito a partir de uma perspectiva outra. É essa inclusive a condição da enunciação.

De nossa parte, gostaríamos de anunciar que é tempo de retornar a

\footnotetext{
${ }^{1}$ Trata-se de "A coisa freudiana ou o sentido do retorno a Freud em psicanálise", republicado nos Escritos (LACAN, 1998 [1966]). Na verdade, o texto é a ampliaçấo de uma conferência proferida por Lacan e em 1955.

${ }^{2} \mathrm{O}$ texto é originalmente publicado em Lettres sur tous les sujets, $\mathrm{n}^{\circ} 12$, em abril de 1994, e republicado em Le périple structural (MILNER, 2008 [2002]).
} 
Benveniste. É urgente que a pesquisa linguística volte ao grande linguista francês que, como declara Agamben (2007, p. 246), "realizou uma nova ‘situaçáo' da linguística”. E quais seriam os termos desse retorno?

Ora, seria demasiado impor condiçóes de leitura a um autor que escapa a qualquer possibilidade apriorística de classificaçáo - vis-à-vis a amplitude de sua obra - em rótulos estanques. No entanto, cabe advertir: há, em Benveniste, muito mais do que nos acostumamos a ver.

A linguística, em geral, muito apressadamente impingiu a Benveniste o rótulo de "linguista da enunciaçáa"; é verdade que, para outros, ele é "o linguista da gramática comparada do século XX"; para outros, ainda, ele é apenas um "generalista". E quem é Benveniste?

Talvez o mais correto fosse responder a essa pergunta com outra: o que não é Benveniste? Para nós, Benveniste não é apenas uma qualificação simplista. Roland Barthes (1984, p. 208, tradução minha), a quem fazemos coro, é um dos primeiros a propagar essa impressão: "o lugar de Benveniste, no concerto dos grandes linguistas que marcam por sua influência todo o trabalho intelectual de nossa época, é completamente original - a ponto de ser, por vezes, me parece, subestimado". E acrescenta: "sua obra é ainda hoje em dia duas vezes paradoxal: no que diz respeito à tradição e no que diz respeito ao que eu chamaria de a vanguarda fácil, aquela que repete ao invés de buscar" (BARTHES, 1984, p. 208, tradução minha).

É essa paradoxalidade que este número da Revista Fragmentum tenta recolocar na ordem do dia. E temos excelentes motivos para fazê-lo. Nos últimos anos, a divulgação de trabalhos do linguista Émile Benveniste até entáo desconhecidos do público em geral - especialmente o livro Dernières leçons: Collège de France 1968-1969, publicado na França em 2012, sob a direçáo de Jean-Claude Coquet e Irène Fenoglio, e traduzido no Brasil em 2014 - aliada a um crescente interesse pelo pensamento do autor em diversas áreas do conhecimento (antropologia, filosofia etc.) fazem crer que estamos vivendo um tempo de renovação de leitura da obra de Benveniste.

Com efeito, o autor tem suas ideias redimensionadas e o alcance de seu pensamento alargado. Essa "nova" realidade está, de certa forma, contemplada neste número da Revista Fragmentum. Nele, encontramos artigos que reconhecem haver uma teoria da linguagem em Émile Benveniste e não apenas uma teoria da enunciaçáo ou uma teoria comparativa. Os temas abordados nos diferentes artigos - inclusive os ligados à chamada teoria da enunciação e à gramática comparada - não ignoram a articulação que têm com um conjunto maior de proposiçóes, o que configura uma teoria geral 
da linguagem.

Os textos, a seguir, revisam e discutem o pensamento de Benveniste sob diferentes enfoques. Assim, Gabriela Barboza, em "'Até o fim de sua vida’: designação e significação em Benveniste”, busca avaliar o papel ocupado pela dupla designaçâo-significação na teoria da linguagem de Émile Benveniste. A análise, baseada nas ocorrências das palavras pesquisadas, mostra que designação e significação assumem papel operador no processo de análise semântica, quando empregados por Benveniste em textos relativos a estudos de comparação de línguas.

Outros textos, por sua vez, retomam o pensamento semiológico de Benveniste. É o caso do artigo de Heloisa Monteiro Rosário, "O Benveniste semiólogo: do labirinto da semiologia à noção de interpretância”, que busca mostrar como Benveniste encaminha uma discussão própria no campo da semiologia, o que envolve a noção de interpretância da língua, elaborada e proposta pelo linguista no final dos anos 1960. Em direção semelhante está o trabalho de Renata Trindade Severo e Nathália Müller Camozzato, "Questôes sobre uma leitura pós-humanista de 'Semiologia da língua”, que analisa a leitura do artigo de Benveniste "Semiologia da língua" operada pela socióloga Vicki Kirby, a fim de evidenciar os conceitos de signo e sistema de significação que estão em jogo tanto na perspectiva pós-humanista de Kirby quanto na perspectiva linguística que privilegia o sentido de Benveniste.

O campo dos estudos benvenistianos em torno da escrita é abordado pelo artigo de Eduardo Alves Rodrigues, Cármen Lúcia Hernandes e Érica Daniela de Araújo, "A teorização de Émile Benveniste sobre escrita: (d) o ponto de vista da vida social". Sob a perspectiva da História das Ideias Linguísticas estabelecida pela prática teórico-metodológica da Análise de Discurso, os autores analisam a teorização sobre escrita empreendida na linguística de Benveniste. Para tanto, buscam reunir condiçôes de compreensão da escrita como forma secundária de fala, a partir de estudo detalhado do recente Últimas aulas no Collège de France (cf. supra). O tema da escrita volta a ser tratado em "O estudo da língua e sua relaçáo com a escrita: projeçôes teóricas de Émile Benveniste”, de Aline Wieczikovski Rocha e Claudia StumpfToldo. Nele, aborda-se a relação semiológica entre o sistema da língua e o sistema da escrita. $\mathrm{O}$ artigo, entre outras contribuiçóes, dá destaque à propriedade semiótica, que reveste o sistema de signos da língua, e à propriedade semântica, que reveste a produçáo do discurso.

A abordagem de Benveniste sobre o discurso poético é objeto de discussão por significativa quantidade de trabalhos aqui publicados. 
Carolina Knack, em “O discurso poético como um 'problema linguístico' nas notas de Benveniste: percursos metodológicos para a abordagem da significaçáo", apresenta uma possibilidade de leitura das notas manuscritas de Émile Benveniste a respeito do discurso poético presentes no dossiê Baudelaire, publicado em 2011, na França. O objetivo é explorar percursos metodológicos delineados pelo linguista para a abordagem do mecanismo da significação desse discurso. Para tanto, a autora identifica categorias de análise e procedimentos metodológicos programaticamente delineados por Benveniste. Em "Dossiê Baudelaire: o encontro da poética de Benveniste com a poética de Meschonnic", Daiane Neumann, com base no mesmo dossiê, busca refletir acerca da relação entre a poética de Émile Benveniste e a poética de Henri Meschonnic. A autora se dedica, também, a estudar os dois volumes de Problemas de linguistica geral, enfatizando, nos livros, o que importa à literatura. Por fim, o trabalho tece consideraçóes sobre o encontro da poética de Benveniste com a poética de Meschonnic, via análise de texto literário. Finalmente, Sabrina Vier, em "Dossiê Baudelaire e a natureza da linguagem poética", por meio do estudo de fólios do dossiê Baudelaire, objetiva problematizar a natureza da linguagem poética. Os resultados apontam que o material do poeta é a palavra-escrita e a palavra-ícone, a unidade do poema. Assim, o poeta dá a emoção e não diz a emoção: a palavra-ícone (imagem e emoção) instaura correspondências suscitadas pela emoção e pela experiência.

Aspectos mais ligados à reflexão da linguística geral de Benveniste são contemplados pelos textos "Linguística da enunciação e distanciamento social: uma reflexão sobre presença e ausência a partir do sistema pronominal", de Charlies Uilian de Campos Silva, "O tempo dos verbos como categoria de análise textual", de Alena Ciulla, e "O que ainda tem a nos dizer Benveniste sobre lingua, linguagem e linguistica em 'Vista d'olhos sobre o desenvolvimento da linguística'?", de Jomson Teixeira da Silva Filho. O primeiro busca compreender como o cenário de distanciamento social está relacionado às reflexôes que formam a teoria enunciativa de Émile Benveniste. Assim, partindo das reflexôes sobre pronomes e discutindo noçóes de pessoa, tempo, espaço e subjetividade, é proposta uma perspectiva teórica capaz de instaurar uma dimensão ética na teoria enunciativa. $\mathrm{O}$ segundo se dedica a reavaliar, sob a perspectiva benvenistiana, o tempo verbal, tradicionalmente classificado em presente, pretérito e futuro. Com base na proposta do autor de distinguir os tempos dos verbos de acordo com a relaçáo que estabelecem com a instância do discurso de quem fala, a autora apresenta uma abordagem inicial de análise do sistema de tempos verbais 
do português, investigando como os planos de enunciação podem estar associados a diferentes modos de conduzir o processus textual. $\mathrm{O}$ terceiro artigo, por sua vez, como sugere seu título, pretende apresentar uma (re) leitura do texto "Vistas d'olhos sobre o desenvolvimento da linguística" de Benveniste, com o intuito de discutir os conceitos de "língua", "linguagem" e "linguística" ali presentes. Para tanto, elege-se, como chave de leitura, o princípio epistemológico segundo o qual, para Benveniste, há uma relação constitutiva entre homem e linguagem, o que configura uma reflexão antropológica.

Vários outros ângulos da teoria benvenistiana são enfocados nos demais trabalhos que integram este número da revista Fragmentum. O artigo "Literatura e enunciação: o eu e o duplo, entre narrador-protagonista e interlocutor, em Grande sertão: veredas", de Fabrício Magalhães de Souza e Juciane dos Santos Cavalheiro, faz uma análise do duplo a partir da relação entre narrador-protagonista e o seu interlocutor em Grande sertão: veredas. O trabalho se baseia em Nicole Bravo - que analisa o duplo como um mito literário característico da literatura ocidental e defende seu surgimento atrelado à experiência subjetiva - e no estudo do sistema pronominal promovido por Émile Benveniste.

Em "A teoria da linguagem de Émile Benveniste: uma abertura para os estudos em aquisiçâo da linguagem”, Carmem Luci da Costa Silva, Giovane Fernandes Oliveira e Marlete Sandra Diedrich defendem que a teoria da linguagem de Émile Benveniste abre possibilidades para os estudos em aquisiçáo da linguagem. Para provar isso, os autores realizam um movimento retrospectivo de retorno às reflexóes benvenistianas sobre a relação da criança com sua língua materna e a escrita dessa língua e um movimento prospectivo com a análise de recortes enunciativos de experiências da criança na linguagem.

Os distúrbios de linguagem são tratados à luz da teoria da linguagem de Benveniste em "Epistemologia enunciativa na clínica fonoaudiológica do autismo", da autoria de Isabela Barbosa do Rêgo Barros e Lorena Grace Alves do Vale. Nesse estudo, as autoras discutem os princípios epistemológicos da teoria enunciativa de Benveniste que podem se fazer presentes na clínica fonoaudiológica que trata o autismo.

Lilian Castelo Branco de Lima, Emanoel César Pires de Assis e Wemylla de Jesus Almeida, em 'Émile Benveniste: 'o homem na língua' entre a linguística, literatura e a antropologia - uma revisão integrativa em pesquisas na pós-graduação do Brasil”, procedem a uma interessante revisão 
integrativa da literatura em dissertaçóes e teses que abordem as ideias de Émile Benveniste e à identificação dos programas de pós-graduação no Brasil aos quais elas são vinculadas. $\mathrm{O}$ objetivo é investigar a incidência com que as obras do autor serviram de fundamentação para as análises desenvolvidas por pesquisadores brasileiros e os diálogos estabelecidos para dar suporte aos estudos dos objetos de pesquisa.

Por último, em "O tradutor Benveniste: uma reflexão a partir de 'La traduction, la langue et l'intelligence', Sara Luiza Hoff e Valdir do Nascimento Flores discorrem sobre a relação de Émile Benveniste com a tradução, tanto enquanto objeto teórico quanto como prática. Para isso, apresentam o manuscrito inédito "La traduction, la langue et l'intelligence", publicado em 2016, em que a traduçáo tem papel de destaque, para, em seguida, considerar as escolhas feitas por Benveniste em uma tradução de um trecho de Moby Dick no texto "Leau virile", de 1945.

Finalmente, esse conjunto bastante expressivo de artigos se encerra com a resenha da autoria de Giovane Fernandes Oliveira a respeito do livro "Émile Benveniste, 50 ans après les Problèmes de linguistique générale", organizado por Giuseppe D’Ottavi e Irène Fenoglio e publicado em 2019.

Como se pode ver, a revista Fragmentum entrega à comunidade científica da linguística brasileira um conjunto de trabalhos que reflete a potencialidade e a atualidade do pensamento de Benveniste. Teríamos cumprido nosso papel ao organizá-lo se o seu conteúdo servisse não apenas para manter, mas também para renovar a presença de Benveniste entre nós.

Uma última palavra de agradecimento gostaríamos de dirigir à equipe da revista Fragmentum, cujos esforços foram incansáveis para viabilizar que este projeto viesse a público.

\section{Referências}

AGAMBEN, Giorgio. Estâncias: a palavra e o fantasma na cultura ocidental. Tradução de Selvino José Assmann. Belo Horizonte: Editora UFMG, 2012. BARTHES, Roland. Le bruisement de la langue - Essais critiques IV. Paris: Seuil, 1984.

BENVENISTE, Émile. Dernières leçons - Collège de France 1968-1969. Paris : EHESS; Gallimard; Seuil, 2012. . Últimas aulas no Collège de France 1968 e 1969. Traduçâo de 
Daniel Costa da Silva et al. São Paulo: Editora Unesp, 2014.

LACAN, Jacques. A coisa freudiana ou o sentido do retorno a Freud em psicanálise. In: ___ Escritos. Tradução de Vera Ribeiro. Rio de Janeiro: Jorge Zahar, 1998 [1966]. p. 402-437.

MILNER, Jean-Claude. Le périple structural: Figures et paradigme. Paris: Verdier, 2008 [2002]. 